\title{
The Prevalence and Side Effect of Nexplanon in Baghdad
}

\author{
Dalya Thamer Ahmed ${ }^{1}$ \\ ${ }^{1}$ Department of Obstetrics and Gynaecology, Al_Iraqia University, Baghdad.
}

\section{ABSTRACT}

\section{BACKGROUND}

Nexplanon is a pregnancy-prevention device that is both safe and reliable. It is a novel reversible long-term contraceptive technique. It's a modern long-acting contraceptive device with a subcutaneous implant that releases etonogestrel (ENG). The main objective of this research was to determine the distribution, tolerability, and adverse reactions of Nexplanon among females who used it in Baghdad and find any relationship between these side effects and the acceptability of the device among contraceptive users.

\section{METHODS}

This study was done via the participation of 80 women who were using Nexplanon at the time of study or had recently removed the implant; the data was obtained from a direct interview and medical records.

\section{RESULTS}

The total number of women enrolled for the study was 80 . The mean age of contributors was $33.24( \pm 2.69)$ years. None of the participants was nulliparous; 15 $\%$ had two children, $85 \%$ had three or more children. Of the participants, $26.25 \%$ and $65 \%$ had secondary and higher education degrees respectively, while only $7 \%$ had primary education and none of the participants had any education. $6.25 \%$ were smokers, only $28.75 \%$ had irregular cycle and the remaining percentage had a regular one. $57(71.25 \%)$ of them underwent adverse events while using the contraceptive implant, the most common one was bleeding disorders most likely in the form of light intermittent bleeding. 69 (86.25 \%) from those only $18(26.08 \%)$ removed implant because of this irritant bleeding, the next common adverse event was headache $44(55 \%), 8(18.18 \%)$ of them removed the implant because of headache, 41 (51.25\%) underwent variable mood swing changes, 36 (45\%) suffered from weight gain with use of the implant, 33 (41.25\%) nausea and bowel habits changes, androgenic effects presented in $19(23.75 \%)$ and $10(12.5 \%)$ in the form of acne and hirsutism, respectively. 3 (10.34\%) of them removed the device as they could not cope with this complication, only $6(7.5 \%)$ suffered from low sexual desire.

\section{CONCLUSIONS}

Nexplanon can be a suitable alternative for women who have been adequately informed about long-term contraception but bleeding disturbances and cycle durations ( $>8$ days) are also key indicators for early removal. The process of consulting the patient and giving them the appropriate educational advice on this subject should be a priority before using the implant, in addition to establishing special induction and educational programs.

\section{KEY WORDS}

Nexplanon, Contraception Method Contraception Method, A Subcutaneous Implant and Etonogestrel.
Corresponding Author: Dalya Thamer Ahmed, Department of Obstetrics and Gynaecology, Al_Iraqia University,

Baghdad.

E-mail: d.alimohamad11@gmail.com

DOI: $10.14260 /$ jemds/2021/747

How to Cite This Article:

Ahmed DT. The prevalence and side effect of nexplanon in Baghdad. J Evolution Med Dent Sci 2021;10(43):3689-3693, DOI: 10.14260/jemds/2021/747

Submission 09-08-2021, Peer Review 10-10-2021, Acceptance 16-10-2021, Published 25-10-2021.

Copyright (C) 2021 Dalya Thamer Ahmed. This is an open access article distributed under Creative Commons Attribution License [Attribution 4.0 International (CC $B Y 4.0)]$ 


\section{BACKGROUND}

Nexplanon is a pregnancy-prevention device that is both safe and reliable. ${ }^{1}$ It is a novel reversible long-term contraceptive technique. It's a modern long-acting contraceptive device with a subcutaneous implant that releases etonogestrel (ENG). It was developed in the United Kingdom and has been available throughout Europe since June 2010.2,3

The new gadget completely replaces the Implanon, which is the world's most popular implantation system. Nexplanon is pharmacologically similar to Implanon since they both include $68 \mathrm{mg}$ of ENG. Further improvements to the Nexplanon applicator appear to ease the operation, for example, inserting the device with one hand and reducing the risk of problems linked to improper insertion, once put at the subdermal level, offer contraceptive coverage to women for at least 3 years. ${ }^{4,5}$

Nexplanon is a recyclable gadget having a single road via which ENG can go. This innovative gadget is shaped like a cylindrical rod with a length of $4 \mathrm{~cm}$ and a thickness of $2 \mathrm{~mm}$. It includes $68 \mathrm{mg}$ of ENG and a central core made up of 37 percent ethylene-vinyl acetate (EVA). Furthermore, the implant's core was enhanced with $15 \mathrm{mg}$ of barium sulfate (3 $\%)$ to make it radiopaque without affecting its pharmacological characteristics. The radio-opacity allows the device to be located using a ray or ultrasound even if it has been placed deeply and is thus not perceptible. ${ }^{6}$

In terms of pharmacokinetic criteria, the Nexplanon operates by continuously releasing subcutaneous ENG (a synthetic progestin molecule), which is the bioactive metabolite of desogestrel (DSG), a third-generation progestin derived from 19-nortestosterone norethisterone (NET), which is also broadly used in oral contraceptives and vaginal rings for contraception. 7,8

Serum levels reach peak levels 4 days after the device is inserted, and then stabilize $(200 \mathrm{pg} / \mathrm{ml})$ after 4-6 months. ${ }^{9}$ Over three years, ENG concentrations stay constant at levels adequate to prevent ovulation. ${ }^{10} \mathrm{~A}$ week following the removal, the levels of ENG are undetectable (less than 20 $\mathrm{pg} / \mathrm{mL})^{10}$

Because ENG levels over the $90 \mathrm{pg} / \mathrm{ml}$ cut-off prevent ovulation, the contraceptive effectiveness is instantaneous. ${ }^{11}$ Moreover the restart is immediate because ovulation may be observed in women 6 weeks after the device is removed. ${ }^{12}$

The ENG works by first suppressing ovulation and then producing morphological and functional changes in the cervical mucus and endometrium. ${ }^{13}$

In aspects of contraceptive effectiveness, unintended gestation resulting from the presence of pregnancies already in progress at the period of implant placement or determined from an improper implant insertion, as well as those resulting from the use of drugs that induce hepatic metabolism or inappropriate scheduling of the procedure. In a hypothetical effectiveness scale, Nexplanon, along with other "long-acting" hormonal devices, stands barely behind tubal sterilization. ${ }^{14}$

Even though the FDA has authorized the use of ENG for the primary intention of contraception, the system does not appear to provide any contraceptive benefits. ${ }^{15}$ So far, several clinical trials have shown that ENG-releasing implants can help with dysmenorrhoea and acne / hirsutism. ${ }^{16}$

Significant decrease in the severity and duration of dysmenorrhea. ${ }^{16,17}$ Although acne and hirsutism are the second non-bleeding associated side events, certain clinical investigations have shown that more than half the women who had acne before the therapy improved their clinical characteristics after implantation. ${ }^{16}$

Specific adverse effects may be linked to the insertion of the device or the discharge of the ENG. ${ }^{2}$ The most often documented side effect is an irregular menstruation pattern, which affects roughly two-thirds of women who have an ENG releasing implant. ${ }^{18}$

The following initial WHO criteria were used to define clinically significant types of bleeding patterns: Infrequent bleeding was defined as less than three bleeding-spotting episodes in a 90-day, excluding amenorrhea; normal frequency was defined as three to five bleeding-spotting episodes in a 90-day; amenorrhea was defined as no bleeding or spotting days throughout the 90-day; More than five bleeding-spotting events in 90 days were classified as recurrent bleeding; persistent bleeding was defined as any bleeding-spotting episode (uninterrupted) lasting for more than 14 days in 90 days. ${ }^{19,20}$

Infrequent bleeding, protracted bleeding, and menometrorrhagia were some of the other bleeding patterns (frequent and heavy bleeding). ${ }^{21}$ Weight increase was observed in around $10 \%$ of women, and it was responsible for $7 \%$ of patient drop-out. 22

Possible side effects related to the use of ENG include psychological problems such as emotional liability and low mood, headache, dizziness. ${ }^{21}$ body weight gain, ${ }^{16}$ discomforts at the implant site, neuropathy, and follicular cysts, ${ }^{1}$ reduced libido, ${ }^{22}$ acne, and hirsutism. ${ }^{2}$

According to a few studies, Nexplanon impacts the incidence or development of sexually transmitted illnesses, as it is linked to an increased chance of getting infections like Chlamydia, but a lower risk of developing other lower genital tract infections (bacterial vaginosis, trichomoniasis and pelvic inflammatory disease). ${ }^{23}$

Medical professionals and patients must be well informed about the potential negative effects of using subcutaneous contraceptives. ${ }^{1}$ It's also crucial to consider the hazards and advantages of each approach. ${ }^{1}$

Nexplanon has just recently reached the Iraqi market, having been introduced by a specific company. More than 200 devices have been utilized from the time of introduction till June 2020, and have been dispersed between Baghdad and other government agencies.

\section{Objectives}

To determine the distribution, tolerability, and adverse reactions of Nexplanon among females who used it in Baghdad and find any relationship between these side effects and the acceptability of the device among contraceptive users.

\section{METHODS}

This is a cross-sectional descriptive study including 80 women who were using Nexplanon at the time of study or had recently removed the implant; the data was obtained from the direct interview and from medical records of outpatient clinics in different Baghdad regions till June 2021. 
The research protocol was reviewed and approved by the Scientific Committee in the College of Medicine /Al-Iraqia University and the Ministry of Higher Education.

\section{Sample Size}

In this study, we reached about 123 women who used the Nexplanon, 110 of them agreed to participate in this study, 3 women refused to enrol into the study, the most common cause of refusal was that they did not have enough time for the interview, other 10 women were missed during the time of the study and 20 women were excluded from this study because they inserted the Nexplanon recently so they did not have any opinion on this matter yet.

\section{Ethical Consideration}

All participants were given informed consent and an abstract about the protocol and the prospective benefits of this study. The significance and purpose of the study were explained to women. Confidentiality of any obtained information was ensured.

\section{Study Tools and Statistical Design}

A special form for the questionnaire prepared by the researcher included several sets of questions. The first set included socio-demographic information like age, educational level, BMI and smoking, another set of questions about reproductive history, another about the menstrual cycle, and other groups included the date of implant placement, the date of its removal (in the case of removal), the duration of its use, the reason for removal and any side effects observed during the use.

The interview took about 20 to 30 minutes, regarding sociodemographic data including age, parity, educational level, smoking state and menstrual history, then date of insertion and if removed, date of removal, cause of removal any side effect or complication during insertion and removal.

Data were collected, tabulated and analyzed by using SPSS (version 23.0 statistical software)

Mean \pm standard deviation and percentage were calculated.

\section{Criteria of Study Population and Exclusive Criteria}

Women who were using Nexplanon at the time of study or had recently removed the implant, all females were of the reproductive age group who used the implant for mainly contraceptive purposes, with the normal menstrual cycle before using the implant and negative gynaecological history for any malignancy or gynaecological disease.

For both groups, all patients with endocrinal abnormalities like thyroid disorder, diabetes, hyperprolactinemia, Cushing's syndrome and cancer were excluded. Pregnant, lactating and menstruating women were also excluded. Patients on any antibiotics oral or vaginal for the last 7 days before the test, no hormonal treatment and no sexual relationship within 48 hours.

For the control group, healthy women whose ages were similar to that of PCOS patients were selected. They visited outpatient clinics for fertility problems or contraceptive purposes. All their physical examination indexes were normal.

\section{RESULTS}

The total number of women enrolled in the study was 80 . Table -1 for sociodemographic data, the mean age of contributors was $33.24( \pm 2.69)$ years. None of the participants was nulliparous; $15 \%$ had two children, $85 \%$ had three or more children. Of the participants, $26.25 \%$ and $65 \%$ had secondary and higher education degrees respectively, while only $7 \%$ had primary education and none of the participants had no education. $6.25 \%$ were smokers, only $28.75 \%$ had irregular cycle and the remaining percentage had a regular one.

Figure 1. This shows that about $13.75 \%$ inserted the Nexplanon for $\leq 1$ year while $65 \%$ used the implant for 2 years and the remaining percent used it for 2-3 years.
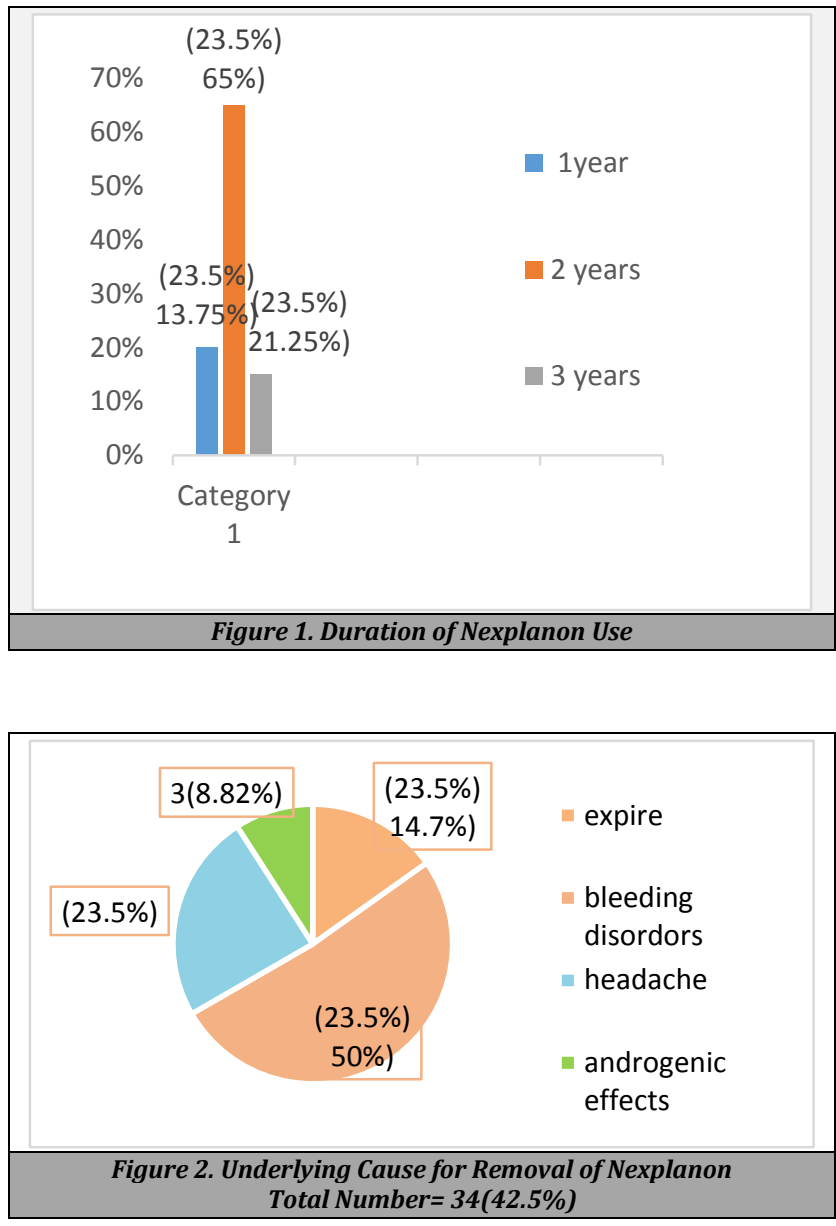

As observed in Figure 2, out of 80 women enrolled in the survey only $34(42.5 \%)$ removed Nexplanon, 5 (14.7\%) because it had expired, thus the discontinuation rate before expiration was 31 (38.75\%), $24 \%$ of them >12 months of use and the remaining between 12 and 24 months.

Of the 34 cases, 18 (50\%) because of bleeding disorders, $8(23.5 \%)$ because of headache and headache caused about 3 $(8.82 \%)$ of the removal rate. 


\begin{tabular}{|c|c|c|c|}
\hline & & $\begin{array}{l}\text { No. or } \\
\text { Mean }\end{array}$ & $\begin{array}{l}\text { \% or } \\
\text { SD }\end{array}$ \\
\hline & Age & 33.24 & \pm 2.69 \\
\hline \multirow{3}{*}{ parity } & Nulliparous or para 1 & zero & zero \\
\hline & 2 children & 12 & $15 \%$ \\
\hline & 3 and more children & 68 & $85 \%$ \\
\hline \multirow{4}{*}{ Educational level } & Primary school & 7 & $8.75 \%$ \\
\hline & Secondary school & 21 & $26.25 \%$ \\
\hline & $\begin{array}{l}\text { College and higher educational } \\
\text { level }\end{array}$ & 52 & $65 \%$ \\
\hline & smoking & 5 & $6.25 \%$ \\
\hline \multirow{2}{*}{$\begin{array}{l}\text { Menstrual history before } \\
\text { insertion of Nexplanon }\end{array}$} & irregular cycle & 23 & $28.75 \%$ \\
\hline & Regular cycle & 57 & $71.25 \%$ \\
\hline
\end{tabular}

\begin{tabular}{|c|c|c|c|c|c|}
\hline & \multicolumn{2}{|c|}{ Yes } & \multirow{2}{*}{$\begin{array}{c}\text { Remove implant } \\
\text { because of this } \\
\text { complication } \\
\text { No. (\%) }\end{array}$} & \multicolumn{2}{|c|}{ No } \\
\hline & No. & $\%$ & & No. & $\%$ \\
\hline Having any side effect & 57 & $71.25 \%$ & $31(38.75 \%)$ & 23 & $28.75 \%$ \\
\hline Bleeding disorders & 69 & $86.25 \%$ & $18(26.08 \%)$ & 11 & $13.75 \%$ \\
\hline Headache & 44 & $55 \%$ & $8(18.18 \%)$ & 36 & $45 \%$ \\
\hline Mood swings & 41 & $51.25 \%$ & & 39 & $58.75 \%$ \\
\hline Weight gain & 36 & $45 \%$ & & 44 & $55 \%$ \\
\hline $\begin{array}{l}\text { Change bowel habits } \\
\text { and nausea }\end{array}$ & 33 & $41.25 \%$ & & 47 & $58.75 \%$ \\
\hline Acne & 19 & $23.75 \%$ & \multirow{3}{*}{$3(10.34 \%)$} & 61 & $76.25 \%$ \\
\hline Hirsutism & 10 & $12.5 \%$ & & 70 & $87.5 \%$ \\
\hline Decrease libido & 6 & $7.5 \%$ & & 74 & $92.5 \%$ \\
\hline \multicolumn{6}{|c|}{ Table 2. Side Effects } \\
\hline
\end{tabular}

In table -2- we can see that 57 (71.25\%) underwent adverse events while using the contraceptive implant, the most common one is bleeding disorder most likely in the form of light intermittent bleeding. 69 (86.25\%) from those only $18(26.08 \%)$ removed implant because of this irritant bleeding, the next common adverse event is headache 44 (55 $\%), 8(18.18 \%)$ of them removed the implant because of headache, $41(51.25 \%)$ underwent variable mood swing changes, 36 (45\%) suffered from weight gain with the use of the implant, 33 (41.2 $5 \%$ ) nausea and bowel habit changes, androgenic effects present in $19(23.75 \%)$ and $10(12.5 \%)$ in the form of acne and hirsutism, respectively. $3(10.34 \%)$ of them removed the device as they could not cope with this complication, only 6 (7.5\%) suffered from low sexual desire while using the implant.

\section{DISCUSSION}

In this survey, we found that Nexplanon was well accepted as it was free from side effects in about more than a quarter of the study population, the remaining was less than 3 quarters represents those have different forms of adverse events, these adverse effects. The side effects led to the removal of the implant before being expired in (38.75\%) of the study sample, this result agreed with the one carried out in Switzerland in 2005 by Johannes Bitzer ${ }^{21}$ as they found the removal rate as $24 \%$, while in Jordan it was $46.4 \% .{ }^{24}$

Bleeding problem was the major reason for removing Nexplanon occurring in $69(86.25 \%)$ women in terms of irregular periods, heavy bleeding and most likely light intermittent bleeding. Our results support previous reports on the reasons for the discontinuation of Implanon, ${ }^{24,25}$ also agree with a survey done in Turkey(26) for women using the implant while breastfeeding as it showed that $30 \%$ of the study sample had abnormal bleeding.

The other most prominent adverse event that led to premature discontinuation was a headache, unlike Moamar Al-Jefout et al. study ${ }^{24}$ wherein they found that the next most common cause was acne, weight gain, and also Johannes Bitzer $^{21}$ as acne had been found as the next most common cause after removal (15\%) and the most common nonmenstrual side effects leading to removal were weight gain and anxiety together in Turkey. ${ }^{26}$

I agree with most previous studies, that other side effects include weight increase, anxiety, breast tenderness, mood swings and decreased libido and none of the implant users conceived while using the method, which reflects the high efficacy of the implant.

About $85 \%$ of users had more than three children, indicating the demography of women who use the subdermal implant as a long-acting contraceptive technique. The same feature was found in Jordan as more than two-thirds of Nexplanon users were having 3 or more children. ${ }^{24}$

In this survey, we found that $>65 \%$ of the study group had good educational level, which indicates the tendency of highly educated class to experience new methods of longacting contraception, this result agreed with most previous studies. ${ }^{24,26}$

\section{CONCLUSIONS}

Nexplanon can be a suitable alternative for women who have been adequately informed about long-term contraception but bleeding disturbances and cycle durations ( $>8$ days) are also key indicators for early removal. The process of consulting the patient and giving them the appropriate educational advice on this subject should be a priority before using the implant, in addition to establishing special induction and educational programs.

\section{Limitations of the Study}

The main limitation of this study was the poor cooperation of patients enrolled in the study; in addition, most of the participants did not have enough time for the interview and the difficulty in reaching all women who had the implants inserted in the past few years in Baghdad. The relatively small sample size in our research is one of its major flaws, this may be due to the collection of data through outpatient clinics and because implant distribution through private companies delivers it to private clinics and not through family planning clinics in government hospitals that cause missing of a lot of data. We propose that the counselling process be given greater attention and that women with extended periods be given another option.

Data sharing statement provided by the authors is available with the full text of this article at jemds.com.

Financial or other competing interests: None.

Disclosure forms provided by the authors are available with the full text of this article at jemds.com.

\section{REFERENCES}

[1] Ramdhan RC, Simonds E, Wilson C, et al. Complications of subcutaneous contraception: a review. Cureus 2018;10(1):e2132. 
[2] Palomba S, Falbo A, Di Cello A, et al. Nexplanon: the new implant for long-term contraception. A comprehensive descriptive review. Gynecol Endocrinol 2012;28(9):71021.

[3] Graesslin 0, Korver T. The contraceptive efficacy of implanon: a review of clinical trials and marketing experience. Eur J Contracept Reprod Health Care 2008;13 Suppl 1:4-12.

[4] Harrison-Woolrych M, Hill R. Unintended pregnancies with the etonogestrel implant (Implanon): a case series from postmarketing experience in Australia. Contraception 2005;71(4):306-8.

[5] Jaffer K, Whalen S. Self removal of Implanon $®$ : a case report. J Fam Plann Reprod Health Care 2005;31(3):248.

[6] Mansour D. Nexplanon (®) : what Implanon (®) did next. J Fam Plann Reprod Health Care 2010;36(4):187-9.

[7] Sitruk-Ware R. New progestagens for contraceptive use. Hum Reprod Update 2006;12(2):169-78.

[8] Sitruk-Ware R, Nath A. Metabolic effects of contraceptive steroids. Rev Endocr Metab Disord 2011;12(2):63-75.

[9] Wenzl R, van Beek A, Schnabel P, et al. Pharmacokinetics of etonogestrel released from the contraceptive implant Implanon. Contraception 1998;58(5):283-8.

[10] Bennink HJ. The pharmacokinetics and pharmacodynamics of Implanon, a single-rod etonogestrel contraceptive implant. Eur J Contracept Reprod Health Care 2000;5 Suppl 2:12-20.

[11] Díaz S, Pavez M, Moo-Young AJ, et al. Clinical trial with 3keto-desogestrel subdermal implants. Contraception 1991;44(4):393-408.

[12] Mäkäräinen L, van Beek A, Tuomivaara L, et al. Ovarian function during the use of a single contraceptive implant: Implanon compared with Norplant. Fertil Steril 1998;69(4):714-21.

[13] Croxatto HB. Mechanisms that explain the contraceptive action of progestin implants for women. Contraception 2002;65:21-27.

[14] Mansour D, Inki P, Gemzell-Danielsson K. Efficacy of contraceptive methods: a review of the literature. Eur J Contracept Reprod Health Care 2010;15(1):4-16.

[15] Food and Drug Administration. Second report on intrauterine contraceptive devices. Washington (DC): Food and Drug Administraction 1978.

[16] Funk S, Miller MM, Mishell DR, et al. Safety and efficacy of Implanon, a single-rod implantable contraceptive containing etonogestrel. Contraception 2005;71(5):31926.

[17] Shokeir T, Amr M, Abdelshaheed M. The efficacy of Implanon for the treatment of chronic pelvic pain associated with pelvic congestion: 1-year randomized controlled pilot study. Arch Gynecol Obstet 2009;280(3):437-43.

[18] Darney P, Patel A, Rosen K, et al. Safety and efficacy of a single-rod etonogestrel implant (Implanon): results from 11 international clinical trials. Fertil Steril 2009;91(5):1646-53.

[19] Belsey EM, Machin D, d'Arcangues C. The analysis of vaginal bleeding patterns induced by fertility regulating methods. World Health Organization Special Programme of Research, Development and Research Training in Human Reproduction. Contraception 1986;34(3):25360.

[20] Belsey EM, Farley TM. The analysis of menstrual bleeding patterns: a review. Contraception 1988;38(2):129-56.

[21] Bitzer J, Tschudin S, Alder J. Acceptability and sideeffects of Implanon in Switzerland: a restrospective study by the Implanon Swiss Study Group. The European Journal of Contraception and Reproductive Health Care 2005;9(4):278-84.

[22] Bitzer J, Tschudin S, Alder J. Acceptability and sideeffects of Implanon in Switzerland: a retrospective study by the Implanon Swiss Study Group. Eur J Contracept Reprod Health Care 2004;9(4):278-84.

[23] Morrison CS, Turner AN, Jones LB. Highly effective contraception and acquisition of HIV and other sexually transmitted infections. Best Pract Res Clin Obstet Gynaecol 2009;23(2):263-84.

[24] Al-Jefout M, Nawaiseh N, Tashman S, et al. Jordanian Women's experience with etonogestrel subdermal contraceptive implant in two family planning clinics. Jordan Medical Journal 2015;49(1):27-35.

[25] Rubenstein J, Rubenstein P, Barter J, et al. Counselling styles and their effect on subdermal contraceptive implant continuation rates. Eur J Contracept Reprod Health Care 2011;16(3):225-8.

[26] Duvan CI, Gözdemir E, Kaygusuz I, et al. Etonogestrel contraceptive implant (Implanon): analysis of patient compliance and adverse effects in the breastfeeding period. J Turk Ger Gynecol Assoc 2010;11(3):141-4. 